\title{
Effect of soaking, autoclaving and repeated boiling on oligosaccharides in cowpea.
}

\author{
Agbenorhevi, J.K., Oduro, I* Ellis, W.O. Abodakpi, V.D. and Eleblu, S.E. \\ Department of Biochemistry and Biotechnology, Kwame Nkrumah \\ University of Science and Technology, Kumasi, Ghana. \\ * Address for correspondence, E-mail : iquomma@yahoo.com
}

\begin{abstract}
Oligosaccharides in beans are known to be the major cause of flatulence associated with beans consumption. The effects of soaking, autoclaving and repeated boiling on the oligosaccharide levels in ten cowpea varieties were studied. The oligosaccharides were extracted in $70 \%$ aqueous ethanol and separated by thin layer chromatography (TLC) method. The quantitation was done using the spectrophotometer. The results showed that, the total oligosaccharide content varies among the cowpea varieties; $0.197-0.918 \mathrm{~g} / 100 \mathrm{~g}$. IT93K-596 had the lowest oligosaccharide content $(0.197 \mathrm{~g} / 100 \mathrm{~g})$ and IT94K-410-2 the highest $(0.918 \mathrm{~g} / 100 \mathrm{~g})$. Autoclaving, soaking and repeated boiling had a reductive effect on the total

oligosaccharides content in the cowpeas used. Autoclaving reduced raffinose level by $23-68 \%$, stachyose level by $12-81 \%$ and total oligosaccharides level by $23-$ $74 \%$. Repeated boiling reduced the raffinose level by $23-$ $61 \%$; stachyose, $20-58 \%$ and total oligosaccharide by 15 $55 \%$. The loss of raffinose and stachyose after soaking ranged from $18.2-53.6 \%$ and $20.4-75.1 \%$ respectively and the total oligosaccharide loss, 25.1-63.9\%. These treatments are therefore recommended for oligosaccharide reduction in cowpeas however their efficiency is variety dependent. These processing methods promise improved utilization or consumption of cowpea in the sense of curbing flatulence associated with beans meal.
\end{abstract}

Key words: Cowpea, oligosacharides, soaking, autoclaving, boiling

\section{INTRODUCTION}

B ean is a common name for large plant seeds of the genera Fabaceae (formerly Leguminosae). Dry beans are widely consumed in most Latin American, Asian and African countries, and for economic reasons are important sources of proteins and calories for those countries (Rayus-Duarte et al., 1998). However, a common complaint of many people after eating a bean meal is the discomfort, and the embarrassment caused by flatulence. This gas (flatulence) is a normal by-product of digestion but when it becomes painful or apparent to others it becomes a physical and social problem (Williams,
1994). Due to the discomfort and social embarrassment of flatulence, some people opt to avoid beans entirely. Oligosaccharides in beans are known to be the flatulence factor (Rackis et al., 1970; Reddy and Salunkhe, 1990). Oligosaccharides are carbohydrates containing between two to ten monosaccharide units (Wardlaw and Insel, 1995; Carey, 2000). There are three main types of oligosaccharides found in beans: verbascose, stachyose and raffinose. Studies have shown that various processing methods such as soaking, autoclaving, fermentation, repeated boiling and 
enzyme treatments have reductive effect on the oligosaccharides and improve the protein digestibility of beans (Barampama and Simard, 1994; Sat and Keles, 2000; Janardhanan et al., 2003). Reduction of oligosaccharides content promises improved utilization of dry beans for human purposes.

In Ghana, cowpea (Vigna unguiculata L. Walp.) which is a type of bean, is one of the most common and cheap foodstuff. It is used to prepare a variety of local dishes/meals such as red-red (beans mixed with palm oil, and gari eaten with fried red plantains), koose or kenka (beans cake), beans stew/ soup, tubani, ayidzenkple, waakye etc. A survey on beans consumption conducted by administering questionnaires to a random sample of 100 people of ages between 10 to 60 years in Accra and Kumasi during the months of June and July, 2005 indicated that $92 \%$ of the people contacted ate beans. Out of this number, $80.4 \%$ of them face one or more related problems such as flatulence, diarrhea, stomach upset, nausea and other problems when they eat beans. The prevalence of flatulence dominates, recording $64.4 \%$. About $80 \%$ of the people desired that the factors causing the problems associated with beans consumption be removed (unpublished data). It is thus evident that many people face one or more problems when they eat beans and paramount among the problems is flatulence (the ' $g a s^{\prime}$ '). Majority of end users desired that a processing method be developed to ease the problem. This project therefore aims at studying the effect of autoclaving, soaking and repeated boiling on oligosaccharides in cowpea.

\section{MATERIALS AND METHODS Sample preparation}

Ten cowpea varieties were obtained from Crop Research Institute, Fumesua-Kumasi, Ghana. Samples were sorted to remove damaged ones, bad ones and unwanted particles. Two hundred grammes of the raw samples for each variety were milled to 60 microns mesh size. The flour samples were then stored in plastic containers at room temperature $\left(25^{\circ} \mathrm{C}\right)$ prior to analysis.

\section{Soaking}

Two hundred grammes of dry cowpeas from each variety were soaked in distilled water in a 1 : $10(\mathrm{w} / \mathrm{v})$ ratio and allowed to stand at $25^{\circ} \mathrm{C}$ for 18 h. After the soaking period, the cowpeas were removed, dried and ground to powder to pass through a mesh size of 60 microns.

\section{Autoclaving}

Two hundred grammes of dry cowpeas from each variety were autoclaved at $1.5 \mathrm{~kg} / \mathrm{cm}^{2}$ pressure at $121^{\circ} \mathrm{C}$ in distilled water (bean: water ratio of $1: 7$ wiv) for $30 \mathrm{~min}$. The seeds were rinsed with distilled water, dried at $55^{\circ} \mathrm{C}$ and ground to powder to pass through a mesh size of 60 microns.

\section{Repeated boiling}

Two hundred grammes of dry cowpeas from each variety were boiled in distilled water (bean: water ratio of 1:10 (w/v)) for $15 \mathrm{~min}$ on a hot plate. At the end of $15 \mathrm{~min}$ period, the water was decanted and boiling in water repeated. At the end of repeated boiling the seeds were rinsed, dried at $55^{\circ} \mathrm{C}$ and ground to powder to pass through a mesh size of 60 microns.

\section{Extraction, TLC separation and estimation of oligosaccharides}

Extractions of oligosaccharides were done based on the method of Somiari and Balogh (1993). Five grams each of both raw and processed (autoclaved, soaked and repeatedly boiled) seed flours of all the varieties were extracted with $50 \mathrm{ml}$ of 70\% (v/v) aqueous ethanol and kept on an orbital shaker at $130 \mathrm{rpm}$ for $13 \mathrm{~h}$. Extracts were then filtered using the Whatman No.1 filter paper. Residue was further washed with $25 \mathrm{ml}$ of $70 \%(\mathrm{v} / \mathrm{v})$ ethanol. The filtrates obtained were then concentrated on a water bath. The concentrated sugar syrup was dissolved in $5 \mathrm{ml}$ of distilled water.

Separation of oligosaccharides was done by thin layer chromatography (TLC). A 100g silica gel was dissolved in distilled water and stirred well until the 
slurry was homogeneous. The TLC plates were washed, dried and cleaned with chloroform to remove any grease from the plates. TLC plates were then coated with the slurry and air-dried. Spotting of the sugar samples was done by using capillary tubes. Each sample was spotted twice separately and dried using electronic hand drier. Sucrose solution was spotted and used as the standard to identify the sucrose bands. The plates were developed by using a solvent system of n-propanol, ethyl acetate and distilled water (6:1:3), and dried (Tanaka et al., 1975). The separated sugars' colours were developed with iodine crystals. The separated spots were compared with the standard sugar spots. The separated sugars that appeared were stachyose, raffinose and sucrose. The stachyose and raffinose spots were scrapped, eluted in $2 \mathrm{ml}$ of distilled water, kept overnight and filtered through Whatman No.1 filter paper. The filtrates were then subjected to quantitative estimation.

The eluted individual oligosaccharides were estimated by the method of Tanaka et al. (1975). One $\mathrm{ml}$ of the eluted and filtered sugar solution was treated with one ml of concentrated $\mathrm{HCl}$. The tubes were boiled in water bath for exactly $6 \mathrm{~min}$. After cooling, absorbances of the oligosaccharide contents were read using Spectrophotometer 259 at 432nm. The absorbance values were used to calculate the concentration and hence mass of the oligosaccharides. Average values of duplicate estimations were calculated and the oligosaccharide contents expressed on dry weight basis.

\section{Statistical analysis}

The data obtained from this study were subjected to statistical analysis (of simple ANOVA) using the Microsoft Excel programme.

\section{RESULTS AND DISCUSSION}

The oligosaccharides found in cowpea were raffinose and stachyose. This is in agreement with the findings of Nwinuka et al., (1997). Tables 1, 2 and 3 show the data on the oligosaccharides content in both raw and processed cowpea samples analyzed. The raffinose level in the raw cowpea ranges between $0.069-0.429 \mathrm{~g} / 100 \mathrm{~g}$. IT93K2732-1 had the highest raffinose level followed by IT94K-410-2 and IT93K-1140 had the lowest amount. The raffinose level in cowpea is comparatively lower than that in Mucuna beans (i.e. $0.95-1.05 \mathrm{~g} / 100 \mathrm{~g}$ ) as reported by Janardhanan et al., (2003). Autoclaved cowpea had lower raffinose levels; the lowest, $0.033 \mathrm{~g} / 100 \mathrm{~g}$ in IT93K1140 and the highest, $0.241 \mathrm{~g} / 100 \mathrm{~g}$ in IT93K-27321. Autoclaving resulted in the reduction of raffinose by $23-68 \%$. The greatest raffinose loss was seen in IT94K-410-2 (68.1\%). The quantity of stachyose in the raw cowpea varied between $0.109 \mathrm{~g} / 100 \mathrm{~g}$ in IT93K-596 and $0.570 \mathrm{~g} / 100 \mathrm{~g}$ in IT94K-410-2. The stachyose levels also decreased after autoclaving $(12-81 \%)$. The highest stachyose loss was found in IT93K-2045-29 (81.1\%). From the study, the stachyose levels in the cowpea were found to be relatively lower than that of Mucuna beans (1.05$1.22 \mathrm{~g} / 100 \mathrm{~g}$ ). It was noted that the stachyose levels were higher than the raffinose levels. Janardhanan et al., (2003) and Sat and Keles (2000) also observed the same trend in their studies on Mucuna beans. IT94K-410-2 recorded the highest amount of total oligosaccharides level $(0.918 \mathrm{~g} / 100 \mathrm{~g})$. Most varieties had levels above $0.50 \mathrm{~g} / 100 \mathrm{~g}$, but IT93K596 and IT93K-1140 had very low levels of $0.197 \mathrm{~g} /$ $100 \mathrm{~g}$ and $0.255 \mathrm{~g} / 100 \mathrm{~g}$ respectively. Autoclaving had a good reductive effect on the oligosaccharides level in the cowpeas. Appreciable loss $(>50 \%)$ were found in IT93K-129-4, IT94K-410-2, IT93K2045-29, IT93K-596 and IT95K-1095-4. IT93K2045-29 had the highest oligosaccharides loss after autoclaving (74.2\%). Repeatedly boiled cowpea had reduced raffinose levels; the least being $0.033 \mathrm{~g} / 100 \mathrm{~g}$ as recorded by IT93K-1140 and the highest by IT95K-1095-4. On the whole, repeated boiling culminated into a general reduction in raffinose levels by $23-68 \%$ and stachyose levels decreased by $20-$ $58.1 \%$, with IT93K-129-4 recording the highest 
percent loss $(58.1 \%)$. Repeated boiling resulted in the highest total oligosaccharide loss of $54.7 \%$. This was obtained in IT94K-410-2, with the least loss of $15.3 \%$ in IT93K-1140. Repeated boiling had a reductive effect on the oligosaccharide content in the cowpea varieties, though none of the varieties recorded a net reduction greater than 55\%. Quite appreciable were the reductions recorded in varieties IT93K-129-4, IT94K-410-2, IT93K-596 and IT95K-1095-4.

Raffinose and stachyose are soluble in water, thus the decreased levels obtained after autoclaving and repeated boiling may be due to leaching into the processing water.The high pressure heating (cooking) attained by the autoclave and the repeated boiling may have facilitated the leaching process and also cause the hydrolysis of raffinose and stachyose to yield the monomer sugar units such as glucose, galactose, fructose and sucrose (Onigbinde and Akinyele, 1983). However, the extent of oligosaccharides loss varied due to varietal differences which affects the genetic make up and degree of absorption..

The soaked samples had raffinose levels ranging from $0.21 \mathrm{~g} / 100 \mathrm{~g}$ to $0.052 \mathrm{~g} / 100 \mathrm{~g}$ for Asetenapa and IT93K-1140 respectively. The stachyose levels recorded for soaked samples ranged between $0.062 \mathrm{~g} / 100 \mathrm{~g}$ (IT93K-596) to $0.325 \mathrm{~g} / 100 \mathrm{~g}$ (IT95K1095-4). A range of $0.134 \mathrm{~g} / 100 \mathrm{~g}$ (IT93K-596) to $0.482 \mathrm{~g} / 100 \mathrm{~g}$ (IT95k-1095-4) was obtained for the total oligosaccharides content. The percent loss of raffinose and stachyose after soaking ranged between $18.2-53.6 \%$ and $20.4-75.1 \%$ respectively and the total oligosaccharides loss between 25.1-63.9\%. IT94K-410-2 had the highest oligosaccharide loss due to soaking. The observed oligosaccharides loss due to soaking was similar to that reported by Sat and Keles (2000). The reduction may be attributed to the solubility of the oligosaccharides in water. When cowpea is soaked, the water is absorbed into the bean, the oligosaccharides get dissolved and leach into the surrounding water. The variation in the reductive effect of soaking can be attributed to the differences in the texture and porosity of the seed coat. In all, the reductions caused by the processing methods do not follow any uniform pattern due to the varietal differences and response to the treatments.

The study showed that IT93K-596 and IT93K1140 had the lowest level of oligosaccharides and after processing, relatively had the lowest level of oligosaccharides. Thus, these varieties can serve as varieties of cowpea to be used if the nutrient content were relatively high or higher than other varieties in the use since their potential to cause flatulence may be low when consumed.

\section{CONCLUSION}

From this study, it can be concluded that the cowpea varieties used exhibited variations in raffinose, stachyose and total oligosaccharide contents. All the processing methods demonstrated a reductive effect on these oligosaccharides. The extent of reduction varied among the varieties and this depended also on the processing method applied. Thus autoclaving, repeated boiling and soaking beans as a processing method, promise improved utilization or consumption of cowpea in the sense of curbing flatulence associated with bean meal. However, the improvement is variety dependent.

\section{REFERENCES}

Barampamma, Z. and Simard, R. E., (1994), Effects of soaking, cooking and fermentation on composition, in vitro starch digestibility and nutritive value of common beans: Plant Foods for Human Nutrition; 48:349 - 365 .

Carey, F. A., (2000), Organic Chemistry, fourth edition, McGraw-Hill companies, USA, p 973.

Janardhanan, K., Gurumoorthi, P., and Pugalenthi, M., (2003), Nutritional Potential of five accessions of a South Indian Tribal Pulse, Mucuna pruriens var 
utilis: The effect of processing methods on the content of L-Dopa, phytic acid and oligosaccharides: Tropical and Subtropical Agroecosystems; 1:141 152.

Nwinuka, N. M., Abbey, B. W. and Ayalogu, E. O., (1997), Effects of processing on flatus producing oligosaccharides in cowpea (Vigna unguiculata) and the tropical African yam bean (Sphenostylis stenocarpa): Plant Foods for Human Nutrition; 51(3): $209-218$.

Onigbinde, A.O. and Akinyele, I.O., (1983), Oligosaccharides content of 20 varieties of cowpea in Nigeria: Journal of Food Science; 48:1250-1254.

Rackis, J. J., Sessa, D. J., Steggerda, F. R., Shimizu, T., Anderson, T. and Pearl, S.R., (1970), Soybean factors relating to gas production by intestinal bacteria: Journal of Food Science; 35:634-639.

Rayus-Duarte, P., Satterlee, L. D., and Romero, A. L., (1998), Enzymatic release of peptides, methionine and cystine from dry beans following heat treatments: Journal of Food Science, 53 (2): 468.
Reddy, N. R. and Salunkhe, D., (1990), Changes in Oligosaccharides during germination and cooking of black gram red and fermentation of black gram rice blends: Cereal Chemistry, 57:356-360.

Sat, I. G and Keles, F. (2002), The effect of soaking and cooking on the oligosaccharides content of seker a dry bean variety ( $P$. vulgaris, $L$ ) Gram in Turkey: Pakistan Journal of Nutrition; 1(5): 206-208.

Somiari, R. T. and Balogh, E. (1993), Effect of soaking, cooking and á-galactosidase treatment on the oligosaccharide content of cowpea flours: Journal of Science Food and Agriculture; 61:339 - 343.

Tanaka, M., Thanakul, D., Lee, T. C. and Chichester, C. O., (1975). A simplified method for the quantitative determination of sucrose, raffinose and stachyose in legume seeds: Journal of Food Science; 40: 1087 - 1088.

Wardlaw, G. M. and Insel, P. M., (1995), Perspectives in Nutrition, Third Edition, WCB McGraw-Hill Companies, Boston, USA, p 80.

Williams, S. R., (1994), Essentials of Nutrition and Diet Therapy, Sixth Edition, Mosby Year Book, Inc, USA, $p 28,38$. 
Table 1: Raffinose in raw cowpea (RC), soaked cowpea (SC), autoclaved cowpea (AC) and repeatedly boiled cowpea (BC). The data are mean mass $(\mathrm{g} / 100 \mathrm{~g})$, standard deviation (SD) and percentage loss (PL) after treatment.

\begin{tabular}{l|c|c|c|c}
\hline Variety & $\begin{array}{c}\text { RC } \\
(\mathbf{g} / \mathbf{1 0 0 g})(\mathbf{S D})\end{array}$ & $\begin{array}{c}\mathbf{S C} \\
(\mathbf{g} / \mathbf{1 0 0 g})(\mathbf{S D})(\mathbf{P L})\end{array}$ & $\begin{array}{c}\mathbf{A C} \\
(\mathbf{g} / \mathbf{1 0 0 g})(\mathbf{S D})(\mathbf{P L})\end{array}$ & $\begin{array}{c}\mathbf{B C} \\
(\mathbf{g} / \mathbf{1 0 0 g})(\mathbf{S D})(\mathbf{P L})\end{array}$ \\
\hline IT93K-129-4 & $0.293(0.009)$ & $0.179(0.004)(38.9)$ & $0.147(0.013)(50.2)$ & $0.147(0.005)(49.8)$ \\
IT94K-410-2 & $0.348(0.004)$ & $0.189(0.055)(45.7)$ & $0.111(0.009)(68.1)$ & $0.137(0.000)(60.6)$ \\
IT93K-2045-29 & $0.150(0.027)$ & $0.121(0.013)(19.3)$ & $0.069(0.005)(54.0)$ & $0.078(0.000)(48.0)$ \\
ASETENAPA & $0.276(0.004)$ & $0.212(0.004)(23.3)$ & $0.173(0.076)(37.3)$ & $0.189(0.009)(31.5)$ \\
IT93K-596 & $0.088(0.032)$ & $0.072(0.009)(18.2)$ & $0.049(0.004)(44.3)$ & $0.039(0.000)(55.7)$ \\
IT93K-1140 & $0.069(0.004)$ & $0.052(0.000)(24.6)$ & $0.033(0.009)(52.2)$ & $0.033(0.000)(52.2)$ \\
IT86K-102-6 & $0.124(0.009)$ & $0.062(0.004)(50.0)$ & $0.088(0.023)(29.0)$ & $0.095(0.013)(23.4)$ \\
IT95K-1095-4 & $0.381(0.012)$ & $0.157(0.009)(58.8)$ & $0.147(0.042)(61.4)$ & $0.234(0.000)(38.6)$ \\
IT93K-2732-1 & $0.429(0.331)$ & $0.199(0.004)(53.6)$ & $0.241(0.009)(43.8)$ & $0.225(0.005)(47.6)$ \\
IT91K-118-2 & $0.182(0.018)$ & $0.099(0.007)(45.6)$ & $0.140(0.014)(23.1)$ & $0.137(0.009)(24.7)$ \\
& & & & \\
\hline
\end{tabular}

Table 2: Stachyose in raw cowpea (RC), soaked cowpea (SC), autoclaved cowpea (AC) and repeatedly boiled cowpea (BC). The data are mean mass $(\mathrm{g} / 100 \mathrm{~g})$, standard deviation (SD) and percentage loss (PL) after treatment.

\begin{tabular}{l|l|l|l|l}
\hline Variety & $\begin{array}{c}\text { RC } \\
(\mathbf{g} / \mathbf{1 0 0 g})(\mathbf{S D})\end{array}$ & $\begin{array}{c}\mathbf{S C} \\
(\mathbf{g} / \mathbf{1 0 0 g})(\mathbf{S D})(\mathbf{P L})\end{array}$ & $\begin{array}{c}\mathbf{A C} \\
(\mathbf{g} / \mathbf{1 0 0 g})(\mathbf{S D})(\mathbf{P L})\end{array}$ & $\begin{array}{c}\mathbf{B C} \\
(\mathbf{g} / \mathbf{1 0 0 g})(\mathbf{S D})(\mathbf{P L})\end{array}$ \\
\hline IT93K-129-4 & $0.358(0.016)$ & $0.285(0.11)(20.4)$ & $0.146(0.041)(59.2)$ & $0.150(0.005)(58.1)$ \\
IT94K-410-2 & $0.570(0.000)$ & $0.142(0.016)(75.1)$ & $0.289(0.005)(49.3)$ & $0.278(0.011)(51.2)$ \\
IT93K-2045-29 & $0.431(0.042)$ & $0.256(0.030)(40.6)$ & $0.081(0.011)(81.2)$ & $0.278(0.320)(35.5)$ \\
ASETENAPA & $0.420(0.078)$ & $0.153(0.031)(63.6)$ & $0.208(0.016)(50.5)$ & $0.296(0.005)(29.5)$ \\
IT93K-596 & $0.109(0.011)$ & $0.062(0.005)(43.1)$ & $0.041(0.005)(62.4)$ & $0.062(0.005)(43.1)$ \\
IT93K-1140 & $0.186(0.159)$ & $0.139(0.011)(25.3)$ & $0.162(0.013)(12.9)$ & $0.146(0.000)(21.5)$ \\
IT86K-102-6 & $0.424(0.267)$ & $0.292(0.009)(31.1)$ & $0.292(0.082)(33.1)$ & $0.278(0.021)(34.4)$ \\
IT95K-1095-4 & $0.519(0.098)$ & $0.325(0.025)(36.4)$ & $0.252(0.036)(50.7)$ & $0.245(0.005)(52.1)$ \\
IT93K-2732-1 & $0.427(0.025)$ & $0.124(0.009)(71.0)$ & $0.350(0.000)(18.0)$ & $0.336(0.010)(21.3)$ \\
IT91K-118-2 & $0.270(0.009)$ & $0.201(0.025)(25.6)$ & $0.204(0.000)(24.2)$ & $0.216(0.005)(20.0)$ \\
\hline
\end{tabular}


Table 3: Total oligosaccharides in raw cowpea (RC), soaked cowpea (SC), autoclaved cowpea (AC) and repeatedly boiled cowpea $(\mathrm{BC})$. The data are mean mass $(\mathrm{g} / 100 \mathrm{~g})$, standard deviation $(\mathrm{SD})$ and percentage loss (PL) after treatment.

\begin{tabular}{l|l|l|l|l}
\hline Variety & $\begin{array}{c}\mathbf{R C} \\
\mathbf{( g / 1 0 0 g})(\mathbf{S D})\end{array}$ & $\begin{array}{c}\mathbf{S C} \\
\mathbf{( g / 1 0 0 g})(\mathbf{S D})(\mathbf{P L})\end{array}$ & $\begin{array}{c}\mathbf{A C} \\
(\mathbf{g} / \mathbf{1 0 0 g})(\mathbf{S D})(\mathbf{P L})\end{array}$ & $\begin{array}{c}\text { BC } \\
(\mathbf{g} / \mathbf{1 0 0 g})(\mathbf{S D})(\mathbf{P L})\end{array}$ \\
\hline IT93K-129-4 & $0.651(0.025)$ & $0.465(0.015)(28.7)$ & $0.293(0.054)(55.0)$ & $0.297(0.009)(54.4)$ \\
IT94K-410-2 & $0.918(0.004)$ & $0.331(0.071)(63.9)$ & $0.400(0.014)(56.4)$ & $0.415(0.011)(54.7)$ \\
IT93K-2045-29 & $0.581(0.429)$ & $0.377(0.043)(35.1)$ & $0.150(0.016)(74.2)$ & $0.356(0.320)(38.7)$ \\
ASETENAPA & $0.696(0.082)$ & $0.365(0.035)(47.6)$ & $0.381(0.092)(45.3)$ & $0.485(0.014)(30.3)$ \\
IT93K-596 & $0.197(0.043)$ & $0.134(0.015)(32.0)$ & $0.090(0.009)(54.3)$ & $0.101(0.006)(48.7)$ \\
IT93K-1140 & $0.255(0.164)$ & $0.191(0.011)(25.1)$ & $0.195(0.022)(23.5)$ & $0.216(0.000)(14.3)$ \\
IT86K-102-6 & $0.548(0.277)$ & $0.354(0.004)(35.4)$ & $0.380(0.105)(30.7)$ & $0.373(0.034)(32.0)$ \\
IT95K-1095-4 & $0.899(0.116)$ & $0.482(0.034)(46.4)$ & $0.399(0.078)(55.6)$ & $0.479(0.005)(46.7)$ \\
IT93K-2732-1 & $0.856(0.356)$ & $0.032(0.014)(62.3)$ & $0.591(0.000)(31.0)$ & $0.561(0.015)(34.5)$ \\
IT91K-118-2 & $0.452(0.028)$ & $0.300(0.032)(33.6)$ & $0.344(0.000)(23.9)$ & $0.353(0.014)(22.0)$ \\
\end{tabular}

